\title{
La excepcionalidad del principio de subsidiariedad en la acción de libertad
}

\author{
The exceptionality of the principle of subsidiarity in the action of liberty
}

\section{Excepcionalidade do princípio de subsidiariedade nas ações de liberdade de movimento}

Artículo recibido en enero 2021

Arbitraje en febrero 2021

Aceptación en marzo 2021

Publicación en abril 2021

\section{Fabiola Beatriz Puch Tórrez}

faby_2011@hotmail.com

https://orcid.org/ 0000-0001-5716-1030 Universidad Autónoma Tomás Frias, Potosí, Bolivia
RESUMEN

\section{ABSTRACT}

RESUMO
El presente documento hace un análisis crítico respecto a la excepcionalidad del principio de subsidiariedad en lo referente a la Acción de Libertad. El objetivo fue analizar críticamente diferentes Sentencias Constitucionales que puntualizan el principio de subsidiariedad excepcional de la Acción de Libertad para tutelar derechos sin perjuicio que exista otro medio o recurso legal. El método utilizado fue el dogmático jurídico al efectuarse un análisis teórico a partir de la revisión de jurisprudencia y normativa. Los resultados develaron que pese a que el Tribunal Constitucional refiere la "subsidiariedad excepcional del hábeas corpus", de forma que la "negligencia (...) de las partes no puede ser salvada por esta jurisdicción", dicha excepcionalidad debería dar lugar a una interpretación restringida, pero en la jurisprudencia parece ser regla general, encuadrándose solo a evitar ese óbice en la Justicia, sin tomar en cuenta que en conclusión se debe primar los derechos fundamentales que acoge y protege la Acción de Libertad.

Palabras clave: Bolivia; Habeas Corpus; Acción de Libertad; jurisprudencia; principio de subsidiariedad excepcional; Sentencia Constitucional

This document makes a critical analysis regarding the exceptionality of the principle of subsidiarity in relation to the Freedom Action. The objective was to critically analyze different Constitutional Sentences that specify the principle of exceptional subsidiarity of the Freedom Action to protect rights without prejudice to the existence of another legal means or resource. The method used was the dogmatic - legal one when carrying out a theoretical analysis based on the review of jurisprudence and regulations. The results revealed that despite the fact that the Constitutional Court refers to the "exceptional subsidiarity of habeas corpus", so that the "negligence (...) of the parties cannot be saved by this jurisdiction", said exceptionality should give rise to a restricted interpretation, but in the jurisprudence it seems to be a general rule, framing itself only to avoid this obstacle in Justice, without taking into account that in conclusion the fundamental rights that the Freedom Action welcomes and protects must prevail.

Key words: Bolivia; Habeas Corpus; Freedom Action; jurisprudence; principle of exceptional subsidiarity; Constitutional Judgment

O objetivo principal da investigação é analisar por meio da identificação da natureza da figura jurídica dos crimes de corrupção incorporados na legislação boliviana. Com metodologia descritiva-proposicional, abordagem qualitativa, e desenho documental, também foram utilizados os métodos analítico, dedutivo e indutivo. A população e a amostra foram constituídas por três peritos, os mesmos que determinaram a sua posição profissional, do ponto de vista doutrinal, pericial e académico da imprescritibilidade dos crimes de corrupção. Como técnicas e instrumentos, utilizou-se a entrevista e um questionário aos especialistas entrevistados. Com isso, obteve-se o efeito na segurança jurídica. Concluindo, que a proposta garantirá o princípio da legalidade e a submissão do controle internacional do cumprimento das obrigações internacionais.

Palavras-chave: Crimes; corrupção; Legislação boliviana; lei 004, transgressão 
INTRODUCCIÓN

La jurisprudencia del Tribunal Constitucional Plurinacional, a propósito del nuevo texto constitucional del 2009, sostuvo que la Acción de Libertad - que a efectos del presente trabajo podrá denominarse indistintamente como Habeas Corpus, refiere que el art. 125 de la Constitución Política del Estado prevé que:

Toda persona que considere que su vida está en peligro, que es ilegalmente perseguida, o que es indebidamente procesada o privada de libertad personal, podrá interponer Acción de Libertad y acudir, de manera oral o escrita, por sí o por cualquiera a su nombre y sin ninguna formalidad procesal, ante cualquier juez o tribunal competente en materia penal, y solicitará que se guarde tutela a su vida, cese la persecución indebida, se restablezcan las formalidades legales o se restituya su derecho a la libertad.

Siendo necesario puntualizar que en resguardo del derecho a la libertad, previsto por el art. 23. I de nuestra Ley Fundamental Constitucional, el Código Procesal Constitucional en su art. 46 estableció:

La Acción de Libertad tiene por objeto garantizar, proteger o tutelar los derechos a la vida, integridad física, libertad personal y libertad de circulación, de toda persona que crea estar indebida o ilegalmente perseguida, detenida, procesada, presa o que considere que su vida o integridad física está en peligro. (Plurinacional, 2013).

Al respecto, el reconocido profesor constitucionalista boliviano José Antonio Rivera Santivañez señala:

la Acción de Libertad, al igual que la Acción de Amparo Constitucional, se constituye en un medio eficaz para limitar el poder del Estado, pues es un freno al exceso, el abuso y la arbitrariedad de la autoridad pública. Sin temor a equivocaciones, se puede afirmar que se constituye en un efectivo instrumento de freno y contrapeso para el ejercicio del poder político. (Plurinacional, SCP 0401/2013-L Expediente 2011-24341-49-AL, 2013).

Citando al efecto lo que deviene en la Sentencia Constitucional 0337/2010-R de 15/06/2010, citado por el Dr. Boris Arias López, la Acción de Libertad se caracteriza por:

1) El informalismo, por la no exigencia de requisitos formales para su presentación; 2) La inmediatez, por la urgencia en la protección de los derechos que tutela; 3) La sumariedad, por el trámite caracterizado ampliamente por la celeridad que le corresponde; 4) La generalidad, pues no reconoce ningún tipo de privilegio, prerrogativas o inmunidades; $y, 5$ ) La inmediación, puesto que en este nuevo contexto, se requiere que la autoridad judicial competente tenga contacto con la persona privada de libertad. (López, 2012). 
Siguiendo las enseñanzas del citado autor y la jurisprudencia constitucional entendió que, ésta acción de defensa se caracteriza por ser: una acción tutelar extraordinaria, porque es única en su género y no forma parte de los recursos ordinarios previstos en la legislación procesal del Estado. Es un proceso constitucional debidos a que de un lado tiene su origen en las normas de la Constitución, y de otro, porque es una acción jurisdiccional creada para, resolver un conflicto o controversia constitucional que se genera con la violación de los derechos fundamentales a la vida y a la libertad física. Finalmente, es de tramitación especial, porque dada su naturaleza tutelar está exenta de los ritualismos y formalismos procedimentales; tiene un trámite sumarísimo, no admite incidentes dilatorios, ni plazos probatorios, toda vez que no es un medio para dirimir ni dilucidar controversias sobre un derecho, sino una vía de reparación o de restablecimiento de los derechos fundamentales a la vida y a la libertad física ante una acción ilegal o indebida de restricción o supresión. Se tramita en única instancia, pues contra el fallo pronunciado por el juez o tribunal competente no procede ningún recurso ulterior.

Sin embargo, hay algo que como tal la misma normativa constitucional, en este caso la Constitución Política del Estado Plurinacional y el Código Procesal Constitucional no toman en cuenta de manera escrita como tal, que es el carácter excepcional subsidiario de la Acción de Libertad, ya que la jurisprudencia constitucional, ha establecido de manera precisa que:

la tutela que concede la acción de libertad, no procede cuando existen o se encuentran pendientes, medios o recursos ordinarios que no han sido agotados, que en el mejor de los casos podrían reparar la vulneración de derechos y garantías, considerando que la acción de libertad no es subsidiaria, por cuanto mediante el desarrollo jurisprudencial que hubo se estableció la concurrencia de la subsidiariedad con carácter excepcional. (Plurinacional, SCP 0401/2013-L Expediente 2011-24341-49-AL, 2013).

Dada la importancia de esta acción de defensa, y el carácter subsidiario que la caracteriza, el presente documento ahonda en esta temática, desarrollando el análisis crítico de algunas de las líneas del Tribunal Constitucional Plurinacional boliviano referidas a la subsidiariedad excepcional de la Acción de Libertad y cuales los mecanismos para flexibilizarla.

\section{Identificación del problema}

Toda vez que el órgano judicial está atravesando por una eminente crisis en la función de administrar justicia, atribuible principalmente a casos de corrupción que se han venido develando, así como la retardación de justicia propiciada por diferentes factores, y la injerencia política en diferentes esferas de poder, que de manera general se traduce en un "abuso de poder público", nuestra sociedad para efectos de garantizar sus derechos recurre a la Acción de Libertad, para la restitución de los derechos que protege esta acción de defensa. 
Sin embargo, conviene reflexionar sobre qué pasa si los derechos que protege el Habeas Corpus (que son fundamentales) merecen un exclusivo tratamiento y por ende es primordial restituirlos sin la necesidad de que existan o se encuentran pendientes medios o recursos ordinarios que no han sido agotados, ya que la jurisprudencia constitucional, ha establecido de manera precisa que, la tutela que concede la Acción de Libertad, no procede sin perjuicio de que existan o se encuentran pendientes medios o recursos ordinarios que no han sido agotados, que en el mejor de los casos podrían reparar la vulneración de derechos y garantías, considerando que la Acción de Libertad no es subsidiaria, constituyendo un óbice para que la justicia constitucional pueda emitir decisión alguna, pues se "podría generar una duplicidad de resoluciones" en ambas jurisdicciones, con un efecto negativo en el proceso de donde emerge la acción tutelar.

Empero de no tutelarse los derechos que resguarda, en donde los bolivianos se encuentran en una situación de indefensión, eh ahí por lo cual se formula la pregunta de investigación relacionada con ¿Cuáles son los mecanismos de flexibilización del principio de subsidiariedad excepcional de la Acción de Libertad para tutelar derechos sin perjuicio que exista otro medio o recurso legal?, por ello, en el desarrollo de este manuscrito es planteado como objetivo analizar críticamente si la Acción de Libertad es procedente sin perjuicio de que existan o se encuentren pendientes medios o recursos ordinarios que no han sido agotados para la protección inmediata de los derechos y garantías restringidos, suprimidos o amenazados de serlo. También, se describirá la acción de libertad y sus procedimientos, para lograr identificar los principios rectores de la acción de libertad, en donde finalmente se considera la posible interposición de la Acción de Libertad sin perjuicio de que existan o se encuentren pendientes medios o recursos ordinarios que no han sido agotados.

En este sentido, el estudio pretende realizar un análisis crítico de diferentes Sentencias Constitucionales que puntualizan el principio de subsidiariedad excepcional de la Acción de Libertad para tutelar derechos sin perjuicio que exista otro medio o recurso legal, ameritando el análisis que puntualiza la Sentencia Constitucional Plurinacional 0401/2013-L:

Dentro de un caso concreto, si una determinada persona en defensa de sus derechos, acudióalajurisdicciónordinariaestandopendienteelpronunciamiento o la toma de una decisión judicial en dicha vía, consiguientemente se encuentra en trámite, ya no es posible acudir a la jurisdicción constitucional; toda vez que, el hecho de existir aspectos pendientes constituye un óbice para que la justicia constitucional pueda emitir decisión alguna, pues se podría generar una duplicidad de resoluciones en ambas jurisdicciones, con un efecto negativo en el proceso de donde emerge la acción tutelar.

Alusión que, desde el punto de vista de la autora del presente documento, considera que pese a que el Tribunal Constitucional refiere constantemente la "subsidiariedad excepcional del hábeas corpus" de forma que la: "negligencia (...) [de las partes] no puede ser salvada por esta jurisdicción", dicha excepcionalidad debería dar lugar a una interpretación restringida, pero en 
la jurisprudencia parece ser regla general; por ello se considera que es menester efectuar el análisis crítico de Sentencias Constitucionales que puntualizan la subsidiariedad excepcional de la Acción de Libertad, es decir, la efectividad del recurso a agotar previamente al planteamiento de la Acción de Libertad, no solo desde el punto de vista normativo y teórico, sino de acuerdo a las particularidades de cada caso concreto.

\section{MÉTODO}

El presente documento corresponde a un tipo de investigación documental y descriptiva. Documental, ya que se realizó una selección y compilación de información a través de la lectura, análisis y crítica de libros, documentos, Sentencias Constitucionales, artículos científicos, normativa como tal, información obtenida de centros de información físicos y virtuales, mismo que coadyuvaron en sustentar y establecer conocimiento respecto a la Acción de Libertad, el carácter subsidiario excepcional de referida acción de defensa. Descriptiva, por la representación detallada de la situación actual de la Acción de Libertad y su carácter excepcional de subsidiariedad, además la descripción de los ejes rectores que caracteriza a citada acción de defensa.

Se empleó el método histórico con la finalidad de conocer los antecedentes de la Acción de Libertad, naturaleza jurídica y los fundamentos que llevaron a esta acción de defensa a cambiar a través del tiempo.

Para lo cual, se analizó y sintetizó Coadyuvó en la construcción del desarrollo del tema, recopilando varias fuentes bibliográficas, descomponiéndolas, analizando y relacionando cada parte, para unirlas y sistematizar los conceptos en el presente documento; además se empleó con la finalidad de comprender la esencia del fenómeno como tal y sistematizar la información necesaria respecto al tema circundante del presente documento, que al efecto es la Acción de Libertad y su carácter excepcional subsidiario.

Como instrumento de investigación se llevó a cabo mediante una ficha de registro, y la técnica empleada fue el registro de revisión documental, con la finalidad de recopilar información de Sentencias Constitucionales referidas a la Acción de Libertad y su carácter excepcional subsidiario, coligiendo y ejemplificando algunas.

RESULTADOS Y DISCUSIÓN

\section{Acción de libertad, concepto, antecedentes, naturaleza jurídica, finalidad, objeto}

\section{Concepto}

Arriata (2017), refiere que:

La Acción de Libertad es la potestad jurídica de una persona individual para pedir ser presentado ante juez para reclamar la tutela a su vida, cese la persecución indebida, se restablezcan las formalidades legales o se restituya su derecho a 
la libertad. Es potestad porque el ser humano y sus derechos subjetivos están protegidos por la ley. La acción es el manto que recubre sus derechos, si se vulnera estos derechos nace la potestad de pedir protección. La acción en sí misma no "vale", se concreta cuando hay pretensión, esto es, si no reclama, no se concreta la acción. La pretensión se concreta con la formalización, si es civil, con una demanda; si es penal, con una querella (denuncia). La acción no tiene validez si no se la ejerce, si no se reclama (s.n.).

La SC 0015/2016-S1, puntualiza que:

...la acción de libertad se constituye en aquel mecanismo de orden constitucional mediante el cual se instaura un procedimiento de protección inmediata, tanto del derecho a la vida, así como de situaciones en las que el derecho a la libertad física de las personas se encuentra lesionada por causa de una persecución ilegal, procesamiento indebido o privación de libertad indebida; en este caso siempre que el ordenamiento jurídico ordinario, no prevea un medio idóneo y expedito para reparar la lesión aducida, puesto que de existir dicho medio, se debe hacer uso del mismo.

En este entendido, la referida acción está dotada de características esenciales que la convierten en el mecanismo idóneo, para la defensa de los derechos que protege; características que bajo la luz de los principios ético morales de la sociedad plural y los valores que sustentan al Estado, redimensionan su naturaleza como acción exenta de formalismos para la consecución de la tutela inmediata, donde el juez constitucional asume un rol fundamental en búsqueda de la verdad material, bajo los principios contenidos en la potestad de impartir justicia, previstos en el art. 178 de la CPE, entre ellos, el de celeridad, servicio a la sociedad, armonía social y respeto a los derechos.

\section{Antecedentes}

Puntualizado por Rosario Arriata en su libro “Acción de Libertad”, infiere que como antecedentes remotos de la Acción de Libertad, se pueden señalar el "In-terdicto de liberisexhibendis et ducendis" otorgado al pater familias (padre de familia) para lograr la devolución al hogar de alguno de sus descendientes y el "Interdictum de homine libero exhibendo". 1. Para reclamar la liberación de un hombre libre dolosamente detenido ambos del antiguo Derecho Romano 2. Un "interdicto" es una acción emitida por el pretor que sirve para interpelar a la autoridad pública a fin de tutelar determinados derechos.

En el Derecho boliviano se puede encontrar en la primera Constitución política de Bolivia 9 (19 noviembre 1826), expresa:

Ningún boliviano puede ser preso sin precedente información del hecho, por el que merezca pena corporal, y un mandamiento escrito del juez ante quien ha de ser presentado, y no podrá pasar de cuarenta y ocho horas sin poner al acusado a disposición del tribunal o juez competente. (Art. 122, Art. 83 inciso 2). 
En 1930, el Gobierno militar de Carlos Blanco Galindo convocó mediante Decreto Ley de 27 de noviembre de 1930 al primer referéndum de la historia nacional celebrado el 11 de enero de 1931, para insertar en la CPE lo siguiente:

Agregase después del artículo $5^{\circ}$ de la Constitución el siguiente: Todo individuo que se creyere indebidamente detenido, procesado o preso, podrá ocurrir por sí o por cualquiera a su nombre, con poder notariado o sin él, ante la Corte Superior del Distrito o ante el juez de partido, a elección suya, en demanda de que se guarden las formalidades legales. La autoridad judicial decretará in-mediatamente que el individuo sea conducido a su presencia y su decreto será obedecido, sin observación sin excusa, por los encargados de las cárceles o lugares de detención. Instruida de los antecedentes, la autoridad judicial, decretará la libertad, hará que se separen los defectos legales o pondrá el individuo a disposición del Juez competente procediendo en todo breve y sumariamente y corrigiendo esos defectos. La decisión que se pronuncie dará lugar al recurso de nulidad ante la Corte Suprema de Justicia, recurso que no suspenderá la ejecución del fallo. Los funcionarios públicos o individuos que resistan a las decisiones judiciales en los casos previstos por este artículo, serán reos de atentado contra las garantías constitucionales, en cualquier tiempo y no les servirá de excusa el haber cumplido órdenes superiores.

Aprobado el texto en el Referendo de 1931 se incluyó formalmente mediante reforma constitucional de 1938. Desde la Ley de 9 de febrero de 2009 se le cambia el nombre de Recurso de "Habeas Corpus" al de Acción de Libertad.

Artículo 125. Toda persona que considere que su vida está en peligro, que es ilegalmente perseguida, o que es indebidamente procesada o privada de libertad personal, podrá interponer Acción de Libertad y acudir, de manera oral o escrita, por sí o por cualquiera a su nombre y sin ninguna formalidad procesal, ante cualquier juez o tribunal competente en materia penal, y solicitará que se guarde tutela a su vida, cese la persecución indebida, se restablezcan las formalidades legales o se restituya su derecho a la libertad.

\section{Naturaleza jurídica}

Al respecto la SC 0008/2010-R, alude que

la Constitución vigente, como eje central del bloque de constitucionalidad imperante, diferencia, derechos fundamentales, garantías jurisdiccionales y acciones de defensa. En esa perspectiva, en su art. 23 garantiza el derecho fundamental a la libertad y los arts. 115. II y 117. I, 119 y 120. I disciplinan los elementos esenciales que configuran la garantía jurisdiccional del debido proceso. La protección eficaz tanto del derecho fundamental a la libertad como de la garantía jurisdiccional del debido proceso, se encuentra resguardada por la acción de defensa denominada "acción de libertad" regulada en los arts. 125 y 126 de esta norma suprema". 
La Declaración Universal de Derechos Humanos, instrumento que forma parte del bloque de constitucionalidad, en su art. 8 establece el derecho de toda persona a contar con un recurso efectivo ante los tribunales competentes para resguardar sus derechos, criterio también recogido por el art. 25 de la Convención Americana de Derechos Humanos.

En el marco de estas declaraciones se determina que la acción de libertad reconocida por la Constitución es un mecanismo breve y sumario destinado a resguardar tanto el derecho a la libertad como el derecho al debido proceso.

Su naturaleza hace que esta acción, frente a otros mecanismos ineficaces, se configure como un medio de defensa idóneo para la protección efectiva y real de derechos fundamentales vinculados a la vida, libertad y procesamientos indebidos que hagan peligrar, supriman 0 restrinjan estos derechos. Esta esencia procesal no difiere a la naturaleza procesal asignada en el art. 18 de la CPE abrg al recurso de hábeas corpus.

De lo expuesto debe establecerse que en caso de existir norma expresa que prevea mecanismos intra-procesales efectivos y oportunos de defensa de estos derechos fundamentales, deben ser utilizados previamente antes de activarse la tutela constitucional, aspecto que se encuentra enmarcado en los mandatos insertos en los arts. 8 de la Declaración Universal de Derechos Humanos y 25 de la Convención Americana de Derechos Humanos.

\section{Objeto}

Arriata (2017) expresa:

El objeto de la Acción de Libertad es: (1) tutelar la vida de una persona, (2) evitar las persecuciones ilegales, (3) remediar los procesos indebidos y (4) restablecer la libertad de locomoción de quien la perdió ilegalmente, de forma inmediata y oportuna. Toda persona que considere que su vida está en peligro, que es ilegalmente perseguida, o que es indebidamente procesada o privada de libertad personal, podrá interponer Acción de Libertad y acudir, de manera oral o escrita, por sí o por cualquiera a su nombre y sin ninguna formalidad procesal, ante cualquier juez o tribunal competente en materia penal, y solicitará que se guarde tutela a su vida, cese la persecución indebida, se restablezcan las formalidades legales o se restituya su derecho a la libertad (s.n.).

El Artículo 46 del Código Procesal Constitucional, alude que:

La Acción de Libertad tiene por objeto garantizar, proteger o tutelar los derechos a la vida, integridad física, libertad personal y libertad de circulación, de toda persona que crea estar indebida o ilegalmente perseguida, detenida, procesada, presa o que considere que su vida o integridad física está en peligro. 
Al efecto también el Artículo 65 de la Ley de Tribunal Constitucional Plurinacional, señala:

Artículo $65^{\circ}$. (OBJETO). Es una acción constitucional extraordinaria de tramitación sumarísima que tiene por objeto la garantía, protección o tutela de los derechos a la vida, a la libertad física y a la locomoción, para el restablecimiento inmediato y efectivo de estos derechos, en los casos en que sean restringidos, suprimidos o amenazados de restricción o supresión.(Bolivia, 2018).

\section{Procedencia}

El Art. 125 constitucional, concordante con el Artículo 47 del Código Procesal Constitucional, puntualizan:

Artículo $125^{\circ}$.- Toda persona que considere que su vida está en peligro, que es ilegalmente perseguida, o que es indebidamente procesada o privada de libertad personal, podrá interponer Acción de Libertad y acudir, de manera oral o escrita, por sí o por cualquiera a su nombre y sin ninguna formalidad procesal, ante cualquier juez o tribunal competente en materia penal, y solicitará que se guarde tutela a su vida, cese la persecución indebida, se restablezcan las formalidades legales o se restituya su derecho a la libertad. (Bolivia, 2018).

\section{Concordante a este:}

Artículo $47^{\circ}$.- (Procedencia) La Acción de Libertad procede cuando cualquier persona crea que: 1 . Su vida está en peligro; 2 . Está ilegalmente perseguida; 3. Está indebidamente procesada; 4. Está indebidamente privada de libertad personal (Bolivia, 2018).

\section{Legitimación}

El Art. 125 constitucional, concordante con el Artículo 48 del Código Procesal Constitucional, puntualizan:

Artículo $125^{\circ}$.- Toda persona que considere que su vida está en peligro, que es ilegalmente perseguida, o que es indebidamente procesada o privada de libertad personal, podrá interponer Acción de Libertad y acudir, de manera oral o escrita, por sí o por cualquiera a su nombre y sin ninguna formalidad procesal, ante cualquier juez o tribunal competente en materia penal, y solicitará que se guarde tutela a su vida, cese la persecución indebida, se restablezcan las formalidades legales o se restituya su derecho a la libertad. (Bolivia, 2018). 
Concordante a este:

Artículo $48^{\circ}$.- (Legitimación activa) La Acción de Libertad podrá ser interpuesta por: 1.Toda persona que considere que su vida o integridad física está en peligro, que está ilegalmente perseguida, indebidamente procesada, presa o privada de libertad, por sí o por cualquiera a su nombre sin necesidad de poder; 2 . La Defensoría del Pueblo; 3. La Defensoría de la Niñez y Adolescencia". (Bolivia, 2018).

\section{Procedimiento}

El Art. 126 constitucional, concordante con el Artículo 49 del Código Procesal Constitucional, puntualizan:

Artículo $126^{\circ}$.- I. La autoridad judicial señalará de inmediato día y hora de la audiencia pública, la cual tendrá lugar dentro de las veinticuatro horas de interpuesta la acción, y dispondrá que la persona accionante sea conducida a su presencia o acudirá al lugar de la detención. Con dicha orden se practicará la citación, personal o por cédula, a la autoridad o a la persona denunciada, orden que será obedecida sin observación ni excusa, tanto por la autoridad - la persona denunciada como por los encargados de las cárceles o lugares de detención, sin que éstos, una vez citados, puedan desobedecer. II. En ningún caso podrá suspenderse la audiencia. En ausencia del demandado, por inasistencia o abandono, se llevará a efecto en su rebeldía. III. Conocidos los antecedentes y oídas las alegaciones, la autoridad judicial, obligatoriamente y bajo responsabilidad, dictará sentencia en la misma audiencia. La sentencia podrá ordenar la tutela de la vida, la restitución del derecho a la libertad, la reparación de los defectos legales, el cese de la persecución indebida o la remisión del caso al juez competente. En todos los casos, las partes quedarán notificadas con la lectura de la sentencia. IV. El fallo judicial será ejecutado inmediatamente. Sin perjuicio de ello, la decisión se elevará en revisión, de oficio, ante el Tribunal Constitucional Plurinacional, en el plazo de las veinticuatro horas siguientes a su emisión. (Bolivia, 2018).

Concordante a este:

Artículo $4^{\circ}$.- (Normas especiales en el procedimiento) La Acción de Libertad se tramitará de acuerdo con el siguiente procedimiento: 1. al momento de interponer la acción, la Jueza, Juez o Tribunal señalará día y hora de audiencia pública, que tendrá lugar dentro de las veinticuatro horas siguientes. Para tal efecto se dispondrá la notificación personal o por cédula a la autoridad o persona accionada. 2. En caso que la persona privada de libertad se encuentre en una cárcel u otro lugar de detención, la Jueza, Juez o Tribunal ordenará también la notificación de la encargada o encargado de dicho centro, para que conduzca a la persona privada de libertad al lugar de la audiencia, en el día y 
hora señalados, disposición que será obedecida sin observación ni excusa. 3 . En caso de peligro, resistencia de la autoridad u otra situación que a criterio de la Jueza, Juez o Tribunal se justifique, podrá decidir acudir inmediatamente al lugar de la detención y allí instalará la audiencia. 4. Cualquier dilación será entendida como falta gravísima de la Jueza, Juez o Tribunal que conoce la acción de conformidad a la Ley del Órgano Judicial, sin perjuicio de la responsabilidad penal que pudiera surgir por el daño causado. 5. Si la audiencia tuviera que celebrarse en sábado, domingo o feriado, la Acción de Libertad será tramitada ante el Juzgado de Turno. 6. Aun habiendo cesado las causas que originaron la Acción de Libertad, la audiencia deberá realizarse en el día y hora señalados, a efectos de establecer las responsabilidades que correspondan". (Bolivia, 2018).

\section{Competencia}

Arrieta (2017) manifiesta que:

...la Acción de Libertad podrá interponerse ante cualquier Jueza, Juez o Tribunal competente, en Materia Penal. El juzgado o tribunal competente será el del lugar en el que se haya producido la vulneración del derecho. Si en el lugar no hubiere autoridad judicial será competente la Jueza, Juez o Tribunal al que la parte pueda acceder por razones de cercanía territorial o mejores condiciones de transporte. Si la vulneración hubiese sido cometida fuera del lugar de residencia de la afecta-da o afectado, ésta o éste podrá presentar la acción, si lo estima pertinente, ante el juzgado o tribunal competente por razón del domicilio".

\section{Requisitos para la acción de libertad}

Arrieta (2017) expresa que:

La acción deberá contener al menos: 1 . Nombre, apellido y generales de quien interpone la acción o de su representan-te legal, acompañando en este último caso, la documentación que acredite su per-sonería. En el caso de terceras personas que tengan interés legítimo, deberán acreditar el interés alegado. Además, deberá indicarse la dirección de un correo electrónico u otro medio alternativo de comunicación inmediata. 2. Nombre y domicilio contra quien se dirige la acción, o los datos básicos para identificarla o identificarlo, así como, en el caso de que se conozca, el lugar dónde pueda ser notificada o notificado. 3. Patrocinio de abogado cuando corresponda, o en su caso la solicitud de defensor público. 4. Relación de los hechos (s.n.). 


\section{Carácter excepcional del principio de subsidiariedad de la acción de libertad}

La Acción de Libertad, consagrada por el artículo 125 de la Constitución Política del Estado Plurinacional de Bolivia, materializa la existencia de un mecanismo constitucional extraordinario de defensa, dotado de un carácter preventivo, correctivo y reparador, cuya función esencial se traduce en la protección inmediata y efectiva de los derechos fundamentales a la libertad física como de locomoción en casos de detenciones, persecuciones, apresamientos o procesamientos ilegales o indebidos por parte de servidores públicos o de personas particulares, así como a la vida, cuando ésta se encuentra afectada o amenazada por la restricción o supresión de la libertad, este razonamiento es concordante con el contenido del artículo 65 de la Ley del Tribunal Constitucional Plurinacional, y artículo 46 del Código Procesal Constitucional estableciendo que el objeto de esta acción extraordinaria es el restablecimiento inmediato y efectivo de los derechos a la vida, a la libertad física y a la locomoción en los casos en que sean restringidos, suprimidos o amenazados de restricción o supresión, entendimiento que, en consideración a la importancia de los derechos protegidos como son los previamente nombrados, implica que de manera general, la acción de libertad no se encuentra regida por el principio de subsidiariedad: al contrario, se activa sin el previo agotamiento de las vías legales ordinarias, es de tramitación especial y sumarísima, reforzada por sus características de inmediatez en la protección, sumariedad, informalismo, generalidad e inmediación, características que permiten colegir que esta acción de defensa extraordinaria, procede contra cualquier servidor público o persona particular y tampoco reconoce fueros ni privilegios, correspondiendo conocer y resolver dicha acción constitucional, al juez en materia penal debido al principio de especialidad reconocido en la Ley Fundamental. No obstante, lo expresado, ante la existencia de medios de impugnación específicos e idóneos para restituir de manera inmediata los derechos objeto de su protección, o bien cuando se activa de manera paralela un medio de defensa previsto en el ordenamiento jurídico, es decir, tanto en la vía constitucional como en la ordinaria, de manera excepcional opera el principio de subsidiariedad.

La sentencia constitucional 0160/2005-R de 23 de febrero de 2005, sentó las incipientes líneas jurisprudenciales sobre la subsidiariedad excepcional en la acción de libertad, estableciendo que en los supuestos en los que existan medios idóneos para reparar de manera urgente y eficaz el derecho a la libertad física ilegalmente restringida, los mismos deben ser utilizados antes de acudir a la justicia constitucional. Dada la naturaleza jurídica de esta acción tutelar y su alcance, a partir de la SC 0160/2005-R de 23 de febrero, se establecieron los supuestos de subsidiariedad excepcional del recurso de acción de libertad, cuando existan medios idóneos e inmediatos para impugnar el supuesto acto o resolución ilegal que vulnera el derecho a la libertad; entendimiento modulado y precisado por el Tribunal en la Sentencia Constitucional 0008/2010-R de 6 de abril, señalando lo siguiente:

El recurso de hábeas corpus, ahora acción de libertad, es el medio idóneo y eficaz para conocer y restituir cualquier tipo de lesión o vulneración que pueda atentar al derecho a la vida, la libertad o constituir una persecución o 
procesamiento indebido que atente o ponga en peligro el derecho a la libertad, cuando de acuerdo a las circunstancias concretas, a pesar de existir mecanismos de protección específicos y establecidos por la ley vigente, éstos resulten ser evidentemente inoportunos o inconducentes, de manera tal que esta acción de defensa, por la urgencia de la situación, se configura como el medio más eficaz para restituir los derechos afectados; empero, en caso de existir mecanismos procesales específicos de defensa que sean idóneos, eficientes y oportunos para restituir el derecho a la libertad y a la persecución o procesamiento indebido, deben ser utilizados previamente por el o los afectados; en estos casos por tanto, la acción de libertad operará solamente en caso de no haberse restituido los derechos afectados a pesar de haberse agotado estas vías específicas.

Del mismo modo, la línea jurisprudencial de la Sentencia Constitucional 0080/2010-R de 3 de mayo, determinó cuándo no es posible ingresar al análisis de fondo de la problemática planteada, al señalar:

Si antes de existir imputación formal, tanto la Policía como la Fiscalía cometieron arbitrariedades relacionadas al derecho a la libertad física o de locomoción, y todavía no existe aviso del inicio de la investigación, corresponde ser denunciadas ante el Juez Cautelar de turno. En los casos en los que ya se cumplió con dicha formalidad procesal, es decir, con el aviso del inicio de la investigación, al estar identificada la autoridad jurisdiccional, es ante ella donde se debe acudir en procura de la reparación y/o protección a sus derechos. De no ser así, se estaría desconociendo el rol, las atribuciones y la finalidad que el soberano a través del legislador le ha dado al juez ordinario que se desempeña como juez constitucional en el control de la investigación.

Por su parte, la Sentencia Constitucional Plurinacional 0003/2012 de 13 de marzo, señaló:

Con la misma lógica, y considerando los nuevos retos de un Tribunal Constitucional Plurinacional, es importante no activar innecesariamente esta jurisdicción, en la nueva coyuntura constitucional plurinacional, se ve la necesidad de fortalecer otros aspectos inherentes al nuevo modelo de Estado plasmado en la Norma Fundamental; por eso mismo, es imperioso que las controversias que podrían conllevar a suscitar una acción constitucional, previamente sean resueltas y respondidas en las instancias establecidas en nuestro ordenamiento jurídico, ya sea un vocal, un juez y el propio Ministerio Público.

En consecuencia, de acuerdo con la jurisprudencia constitucional señalada, la Acción de Libertad no puede constituirse en un medio adicional o supletorio que pueda ser activado cuando no se hizo uso oportuno de los mecanismos ordinarios de defensa instituidos por el ordenamiento jurídico, cuando aquellos fueron activados extemporáneamente o cuando se pretende obtener un pronunciamiento más rápido sin el previo agotamiento de las instancias respectivas en la 
jurisdicción ordinaria, pues conforme se ha sostenido, la presente vía, se caracteriza por ser un medio eficaz de defensa de los derechos y garantías de carácter excepcionalmente subsidiario, que únicamente opera cuando no existe otro medio de protección judicial.

Sin embargo, en lo particular, debe observarse que el uso de la subsidiariedad en la jurisprudencia puede tergiversarla; así, se tiene que:

- En la Sentencia Constitucional 0134/2010-R la falta de apelación a la resolución que supuestamente afectaba la libertad dio lugar a:

... asumir como lógica consecuencia a este Tribunal que, el accionante estuvo conforme con la decisión, toda vez que no utilizó un recurso expedito en resguardo del derecho que invoca y acudió directamente a la justicia constitucional, garantía que podrá ser utilizada sólo cuando el Tribunal superior en grado no haya reparado las lesiones denunciadas, lo que determina la denegatoria de la tutela, por subsidiaridad.

Mientras que en la Sentencia Constitucional 0856/2010-R se denegó la tutela porque la parte accionante retiro su apelación a la resolución que presuntamente lesionaba su libertad haciendo

... presumir, lógicamente, que el accionante estuvo conforme con la decisión inicialmente impugnada, toda vez que no permitió que se resuelva un recurso expedito en resguardo de su derecho a la defensa que él mismo había activado y que inclusive lo habilitaba para interponer posteriormente recurso de hábeas corpus, hoy acción de libertad", cuando en todo caso únicamente debió referirse al principio de subsidiariedad, o en la Sentencia Constitucional 0783/2010-R, donde el accionante se encontraba detenido preventivamente y por solicitar dos veces su cesación a la detención preventiva se entendió que acepto: “(...) implícitamente su aprehensión ordenada por la Fiscal demandada y (...) la medida cautelar de detención preventiva que fue impuesta.

Cuando en todo caso debió aplicarse el principio de preclusión que no fue aun suficientemente analizado en este tipo de recursos.

- En la Sentencia Constitucional 080/2010-R se sostuvo que contra decretos dilatorios no era necesario agotar previamente al planteamiento de la Acción de Libertad el recurso de reposición, por entenderse inidóneo, pero al mismo tiempo se estableció que se inviabilizaba una Acción de Libertad mientras se tramitaba la reposición, situación que obligaba a agotar un recurso que anteriormente se consideró inidóneo.

- Asimismo, por regla general de la jurisprudencia ante la activación de la vía ordinaria y la constitucional de forma paralela para reguardar la libertad, se procede a denegar de manera automática la tutela de la Acción de Libertad a fin de evitar una intromisión en los órganos ordinarios, quedando establecido que: 
... aún en el supuesto de que dicho medio o recurso no sea el más idóneo, eficaz o inmediato, es lógico suponer que tampoco procede esta acción tutelar en aplicación de la excepción de subsidiariedad, ello debido a que el recurrente, actual accionante, no puede activar dos jurisdicciones en forma simultánea para efectuar sus reclamos, no siendo admisible dicha situación que de ocurrir inviabiliza la acción tutelar, pues al activar en forma simultánea la jurisdicción ordinaria y la jurisdicción constitucional, para que ambas conozcan y resuelvan las irregularidades denunciadas, se crearía una disfunción procesal contraria al orden jurídico.

Sin la valoración de la idoneidad del recurso a agotar (teórico y en el caso concreto).

- A veces se da un uso confuso a la subsidiariedad; en la Sentencia Constitucional 0462/2010-R, ante el rechazo del juez a una solicitud de extinción de la acción penal por máxima duración del proceso, en lugar de sostenerse que la Acción de Libertad era improcedente por no ser la causa directa de la privación de libertad se alegó que no se agotó la apelación, o en la Sentencia Constitucional 0706/2010-R, ante la denuncia de irregularidades en la aprehensión cuyo tratamiento es la de un incidente y pese a que todavía no existía la línea jurisprudencial en sentido de que pueden apelarse los incidentes se sostuvo que:

... si la parte considera que aún existe la vulneración a su derecho de locomoción por parte del Fiscal demandado, dicha Resolución puede ser apelada conforme dispone el art. 251 del CPP y sólo una vez agotada esa instancia y ante una inminente vulneración del derecho a la libertad no resuelta por las autoridades jurisdiccionales ordinarias, es posible acudir al recurso de hábeas corpus.

\section{CONCLUSIONES}

La Acción de Libertad, se materializa como la existencia de un mecanismo constitucional extraordinario de defensa, dotado de un carácter preventivo, correctivo y reparador, cuya función esencial se traduce en la protección inmediata y efectiva de los derechos fundamentales a la libertad física como de locomoción en casos de detenciones, persecuciones, apresamientos o procesamientos ilegales o indebidos por parte de servidores públicos o de personas particulares, así como a la vida, cuando ésta se encuentra afectada o amenazada por la restricción o supresión de la libertad.

En caso de existir mecanismos procesales específicos de defensa que sean idóneos, eficientes y oportunos para restituir el derecho a la libertad y a la persecución o procesamiento indebido, deben ser utilizados previamente por el o los afectados; en estos casos por tanto, la acción de libertad operará solamente en caso de no haberse restituido los derechos afectados a pesar de haberse agotado estas vías específicas. 
Después del análisis de diferentes Sentencias Constitucionales emergentes del Tribunal Constitucional Plurinacional de Bolivia, todo se reduce a que pese a que el Tribunal Constitucional refiere constantemente la "subsidiariedad excepcional del hábeas corpus", de forma que la: "negligencia (...) de las partes no puede ser salvada por esta jurisdicción", dicha excepcionalidad debería dar lugar a una interpretación restringida, pero en la jurisprudencia parece ser regla general, encuadrándose solo a evitar ese óbice en la Justicia, sin tomar en cuenta que se debe primar los derechos fundamentales que acoge y protege la Acción de Libertad.

\section{REFERENCIAS}

Arriata, R. (2017). Acción de libertad. Apuntes Jurídicos.

Bolivia, T. C. (2018). Constitución Política del Estado.

BOLIVIA, T. C. (2018). Constitución política del Estado; Ley del Tribunal Constitucional Plurinacional; Código procesal constitucional
López, B. A. (2012). El informalismo de la acción de libertad. Revista Científica Javeriana, (125), 53-82

Plurinacional, T. C. (2013). SCP 0401/2013-L Expediente 2011-24341-49-AL.

Plurinacional, T. C. (2013). SCP 0401/2013-L Expediente 2011-24341-49-AL. 